\title{
Long-Term Trends in Depression Among Women Separated From Abusive Partners
}

\author{
DEBORAH K. ANDERSON \\ DANIEL G. SAUNDERS \\ MIEKO YOSHIHAMA \\ University of Michigan \\ DEBORAH I. BYBEE \\ CRIS M. SULLIVAN \\ Michigan State University
}

This study tested a cumulative adversity hypothesis, where differences in postseparation stressors among battered women were expected to lead to a widening gap in levels of women's depression over time. Ninety-four women separated from their abusive partners were interviewed six times over a 2-year period. Consistent with the hypothesis, inequalities grew over time. Women who were exposed to the greatest amount of violence and secondary stressors shortly after shelter exit experienced relatively higher levels of depression that either did not improve or significantly increased with time. Social support was the only resource to have the hypothesized decreasing effect on depression.

Keywords: battered women; depression; leaving abusive relationships; stress

The negative effects of domestic violence on survivors' psychological well-being are widely documented (Campbell \& Lewandowski, 1997; Golding, 1999). However, little is known about the psychological well-being of women in the aftermath of separation from their abusive partners. Although some women may experience a sense of relief and greater well-being after leaving, there is some evidence to suggest that many women who leave their abusers are often under considerable distress. Studies have found that

AUTHORS' NOTE: This research was supported in part by the National Institute of Mental Health Grant R01 MH 44849 to William Davidson and Cris M. Sullivan. The authors wish to thank the women who participated in this study. In addition, we wish to thank Kathy Welch for her role in providing excellent statistical consultation. Thanks also goes to Ruth Fleury for providing assistance with some data management tasks.

VIOLENCE AGAINST WOMEN, Vol. 9 No. 7, July $2003 \quad 807-838$

DOI: $10.1177 / 1077801203253401$

(C) 2003 Sage Publications 
average levels of depression and post-traumatic stress disorder (PTSD) among such women can equal (Herbert, Silver, Cohen, \& Ellard, 1991; Rounsaville, 1978) or exceed (Kemp, Green, Hovanitz, \& Rawlings, 1995; Lerner \& Kennedy, 2000; Walker, 1984) those of women still involved in abusive relationships. One recent study found that depending on the measure used, $44 \%$ to $66 \%$ (55) of women separated from an abusive partner an average of 9 years continued to experience some PTSD symptoms (Woods, 2001). If many women who separate from their partners are highly distressed, enhanced understanding is needed about the relevant risk and protective factors affecting their psychological well-being.

Life circumstances at the time of separation affect the degree to which relief and other emotions are experienced. From the standpoint of a stress-process model (Pearlin, Lieberman, Menaghan, \& Mullan, 1981), separation is a critical time in that it sets in motion numerous, sudden, and often, dramatic environmental changes in various areas of a woman's life. The current investigation considered how women vary with respect to four categories of variables: the primary stressor that sets the stress process in motion (male violence), secondary stressors that follow the primary stressor chronologically (e.g., emotional and financial losses, family life changes), coping resources that can be used to buffer stressful events (Aneshensel, 1999), and the resulting level of depression. Stress-process models help to explain why individuals experiencing a similar primary stressor can experience very different consequences (Pearlin, 1999a, 1999b). The current investigation extends Pearlin's (1999a, 1999b) theoretical work on the dynamics of the stress process by describing some types of response patterns that are a result of this process. Specifically, we focused on the patterns of change in women's levels of depression following separation from an abusive partner.

Few studies have addressed patterns of change in depression or other aspects of well-being following trauma. Some longitudinal studies (Turner \& Roxburgh, in press) and reviews (Turner \& Wheaton, 1995) have found that the effects of many ordinary stressors, such as those found on life events and daily hassles checklists (e.g., see DeLongis, Folkman, \& Lazarus, 1988; Holmes \& Rahe, 1967), appear to be relatively short lived, with those experiencing a stressful event returning to previous levels of 
functioning in a matter of a few weeks or months (Solomon, Oppenheimer, \& Noy, 1986). Theoretically, initial differences in well-being among those differentially exposed to stressors would diminish or disappear within this time frame. This response pattern is referred to as "homeostasis," in which there is a temporary crisis or "imbalance" between the excessive demands from the environment and the individual's "response capability" (McGrath, 1970).

In contrast, the disruptions caused by traumatic stressors, such as violence by an intimate partner, are believed by some researchers to trigger other events or more enduring strains that put an individual at an ever greater risk for negative mental health consequences (e.g., Cherlin, Chase-Lansdale, \& McRae, 1998; Hoffman, Cerbone, \& Su, 2000; Pearlin, 1999b; Pearlin et al., 1981; Wheaton, 1999; Wheaton \& Gotlib, 1997) and could potentially follow a very different response pattern or trajectory. Domestic violence and subsequent separation from the abuser are likely to have many negative outcomes because it often entails multiple secondary stressors, repeated exposures to violence, and limited access to key social, financial, material, and internal coping resources for many women. The differing levels of stressors and coping resources at the time a woman leaves an abusive relationship could set in motion a cumulative process of further resource depletion and greater vulnerability to (or resource gain and protection from) future stress. Rather than a return to pretrauma levels of functioning, exposure to such stressors could trigger a spiral of increasingly negative (or positive) changes in psychological well-being for some people. The trend, in other words, is one of increasing divergence in well-being over time among more and less stressed individuals (Aldwin \& Stokols, 1988). Some have termed this pattern of change over time cumulative adversity or disadvantage in other populations (e.g., Singer, Ryff, Carr, \& Magee, 1998; Zuckerman, 1998).

Empirical evidence concerning such trajectories in well-being is largely absent in research on battered women, especially for those who have separated from their abusers. Nevertheless, in several cross-sectional or short-term, longitudinal studies, trauma symptoms did decrease with time since separation for battered women (e.g., Dutton \& Painter, 1993) with some exceptions (Rollstin \& Kern, 1998). These findings are backed by long- 
term longitudinal studies on nonbattered divorcing women (e.g., Kiecolt-Glaser et al., 1987; Pledge, 1992; Shapiro, 1996; Wilcox, 1986). However, studies reporting only overall mean levels of psychological well-being may mask substantial variations in mental health outcomes among the separated. It has been well established in studies of sexual assault that although mean distress levels improve dramatically over the course of several months (e.g., Koss \& Mukai, 1993; Neville \& Heppner, 1999; Resick, 1993), there is a good deal of individual variation. Some rape victims continue to report elevated levels of depression and anxiety for years or decades (e.g., Koss \& Mukai, 1993; Resick \& Nishith, 1997). Similarly, a majority of divorcing men and women in Kitson's (1992) study $(n=129)$ reported higher $(54 \%)$ or unchanged (19\%) levels of psychological adjustment from the time of the filing to approximately 3.5 years later, but the scores of a substantial minority worsened over time (27\%). Possible reasons for differential change in adjustment, however, were not directly investigated.

Separated battered women report a variety of experiences that are likely to lead to different mental health outcomes. National crime surveys and stalking studies indicate that many battered women continue to experience ongoing or escalated abuse after leaving (e.g., Johnson, 1995; Mechanic, Weaver, \& Resick, 2000; Tjaden \& Thoennes, 2000). Moreover, to varying degrees, most separating women face secondary stressors that simultaneously involve multiple losses and new or altered responsibilities. A small body of research that borrows from the bereavement literature suggests that battered women frequently experience a normal grieving response after separation (e.g., Molina, 1999; Rosen \& Stith, 1997), regardless of the desire to end the relationship. Attachment and loss have been shown to relate to higher levels of depression or psychological distress in divorcing women (e.g., Berman, 1988; Brown \& Foye, 1982; Caldwell \& Bloom, 1982; Kiecolt-Glaser et al., 1987). In addition, data from national samples estimate that following divorce, women experience declines in economic well-being that average about $30 \%$, or $36 \%$ if there are young children in the household (e.g., Bianchi, Subaiya, \& Kahn, 1999; Duncan \& Hoffman, 1985). Poverty rates are similar for custodial mothers who are receiving child support (Bartfield, 2000). The declines in income (relative to needs) are greater than $50 \%$ for 
more than one quarter of single mothers (Bianchi et al., 1999). Such losses in income, housing, and financial security, among other losses following divorce are related to lower levels of psychological well-being among women (Berman, 1988; Sato \& Heiby, 1992). Still other research has found lower levels of psychological well-being in divorcing women who experience greater conflicting demands of the single parent and provider roles (e.g., Thiriot \& Buckner, 1992). Family maintenance demands may increase largely due to numerous changes in family composition, roles, and relationships as well as children's difficulties in understanding and adjusting to these changes (e.g., Buehler, Hogan, Robinson, \& Levy, 1985; Dixon \& Rettig, 1994; Gerstel, Riessman, \& Rosenfield, 1985; Humphreys, 1995; Tutty, 1998).

Findings from qualitative studies suggest that some women continue to suffer from the effects of the violence, as well as secondary complications stemming from the separation, from at least 5 years (Hoff, 1990; Thabes, 1997) to 20 years postseparation (Roberts, Williams, Lawrence, \& Raphael, 1998). However, a number of studies have found that female sexual assault victims who are at risk for long-term clinical levels of distress can be identified with considerable accuracy by the intensity of their psychological reactions in the first several weeks posttrauma (e.g., Koss \& Mukai, 1993; Resick \& Nishith, 1997). Similarly, it is likely that we can identify battered women who will require a relatively longer period of recovery and are at greater risk of getting caught in downward spirals in well-being.

Only one study has addressed cumulative adversity among battered women, although it was not conceptually couched in those terms. Findings from Campbell and Soeken's (1999) study support the hypothesis that the negative effects of domestic violence on women's well-being can be cumulative. Not only did the relative gap in physical health and self-care agency increase over time between women who experienced abuse over the fewest and most time points, but also the actual levels of well-being for these measures decreased for those experiencing abuse at all three time points over a 3.5-year period. The results of several retrospective studies are also suggestive of cumulative adversity in battered women. The number of different types of childhood and adult victimization, including abuse by an intimate partner, were significantly related to more adverse trauma-specific outcomes in 
samples of women recruited from both clinical and nonclinical settings (Follette, Polusny, Bechtle, \& Naugle, 1996; Roberts et al., 1998; Weaver \& Clum, 1996; Yoshihama \& Horrocks, 2002). Unfortunately, the role of resources in promoting well-being was examined in only one study, which found positive effects (Yoshihama \& Horrocks, 2002).

Access to key social, financial, material, and internal coping resources is deemed by some investigators to be crucial because their presence in sufficient quantities is required for the maintenance of psychological well-being. Henderson's (1992) review of the literature on the social support-depression link suggests that low levels of resources, such as social support, are stressful and can contribute to the onset of depression. Many battered women, especially in shelter samples, do not have ready access to basic necessities at the time of separation, including food, clothing, and housing (Sullivan, Basta, Tan, \& Davidson, 1992). Although resources appear to be essential in any case, they may be especially pertinent to warding off stress in times of crisis (e.g., Hobfoll, 1989; Hobfoll, Dunahoo, \& Monnier, 1995), and there is some evidence that the positive effects are most keenly felt among those who are under the greatest stress (Henderson, 1992; Yoshihama \& Horrocks, 2002).

The present study assessed the impact of various stressors and resources on battered women's depression among those who remained separated from their abusers for at least 24 months. We sought to identify which battered women were most likely to experience higher levels of long-term depression. In keeping with the cumulative adversity hypothesis, we predicted (a) that the women who were exposed to the highest levels of stress (in the form of violence and secondary stressors) shortly after the time of shelter exit would report higher levels of long-term depression and (b) that the relative differences in depression among women exposed to the most and least overall stress (i.e., the upper third and lower two thirds of the sample) would increase over the 2year period. In addition, coping resources were expected to contribute to decreased levels of depression, especially for the highstress women. Both the main and interactive effects of resources were tested. The impact of stressors and coping resources was assessed in terms of whether the hypothesized effects were cumulative in a way that could contribute to downward or upward 
spirals in depression. Of practical significance is the following question: Can the most vulnerable separated survivors be identified early so that intervention can occur before their condition becomes chronic or worsens?

\section{METHOD}

\section{DESIGN AND PROCEDURES}

This study was part of a larger research project that used an experimental design to assess the effects of a 10-week advocacy intervention for women exiting a battered women's shelter (Sullivan, Campbell, Angelique, Eby, \& Davidson, 1994). Over a 13-month period, all women who stayed at a shelter for at least one night and planned on residing in the general area for 10 weeks after leaving the shelter were asked to participate in the study. Women were interviewed a total of six times over a 26.5-month period: immediately postshelter (Time 1), 10 weeks later (Time 2), and every 6 months thereafter (Time 3 through Time 6). Participants were interviewed in the community, generally in their own homes, by project staff as well as undergraduate university students who received extensive training in return for college credits. Women who agreed to participate were paid progressively more with each interview completed, from $\$ 10$ to $\$ 100$. Of those eligible, $93 \%$ agreed to take part in the study. Half of these women were randomly selected to receive the free services of advocates. Strategies for tracking women over time resulted in a $97 \%$ retention rate (i.e., those who provided some data) over the 2-year period for a total of 278 women at Time 6 .

\section{RESPONDENTS}

The current study focused on a subsample of women from the original sample. Included were those women who (a) were not intimately involved with the original assailant at any of the six time points and (b) had recently been in a committed, heterosexual relationship with their assailant prior to their shelter stay (i.e., married and living together, married and separated, divorced, girlfriend and boyfriend, ex-girlfriend and ex-boyfriend, or the abuser contributed to their household income in the past year). 
The theoretical framework and research reviewed below is most applicable to women who are leaving committed relationships because legal and/or financial ties are assumed. Hence, excluded from the analysis are women who reported being involved with the abuser at any of the time points or who had only been casually dating their abusers (not as girlfriend). Also, excluded were 2 lesbian women. Not only are there differences in the social context and the dynamics of lesbian domestic abuse compared to male heterosexual violence, but also the effects of lesbian abuse on the victim's adjustment may be compounded by homophobia, both external and internalized (e.g., Balsam, 2001; Miller, Green, Causby, White, \& Lockhart, 2001; Tigert, 2001). Of the 97 women who fit the selection criteria, 3 were excluded from the analysis due to missing data on one or more of the stressors. Results of this study are based on the information given by the remaining 94 women.

There was a nearly even division between women who participated in the advocacy intervention (55\%) and those in the control group $(45 \%)$. These proportions did not differ significantly from those of the overall sample. The women tended to be fairly young and poor, with a mean age of $28(S D=7.31)$ and an average annual household income of $\$ 12,420(S D=10,513)$ in the year preceding this study. Although the majority were receiving public assistance at the time of shelter exit (83\%) and had dependent children younger than 18 living with them (76\%), a sizeable minority were employed (26\%) and had at least a high school education (34\%) or some college (30\%). Only $27 \%$ had access to a car. In addition, a large proportion of minority women comprised this sample (50\% Black, 39\% White, and 11\% Hispanic, Asian, or other). Prior to their shelter stay, a majority of study participants had been in a cohabiting relationship with their abusers $(62 \%)$, while the others were married and living with the abuser $(20 \%)$, married and separated $(11 \%)$, divorced $(3 \%)$, or had otherwise been involved with the abuser (4\%) (e.g., noncohabiting girlfriend). Finally, most of the women had been severely abused at Time 1 . More than half $(58 \%)$ said they had been forced into sex by the abuser in the 6 months prior to their stay at the shelter, $46 \%$ had been threatened with a gun or knife, and 95\% had sustained injuries. Almost half $(46 \%)$ reported further abuse by the same assailant during the 
26-month postshelter period between the Time 1 and Time 6 interviews.

\section{MEASURES}

\section{Stressors}

We examined two types of stressors that seemed most relevant to separated battered women: (a) the violence and (b) secondary stressors stemming from the separation, including attachment/ loss, income loss, and family responsibilities. We were primarily interested in women's sum total exposure to these two kinds of stressors near the time of shelter exit because cumulative adversity is believed to be most likely to result from the combined effects of multiple major stressors.

\section{Partner Violence}

A modified and expanded version of the Conflict Tactics Scale (CTS) physical aggression subscale (Straus, 1979) was used to assess respondents' experiences of physical violence, which ranged from a grab or a slap to choking and the use of a weapon such as a knife or a gun. Revisions were made to the CTS items in the time frame and the response category frequencies. Women reported on the violence perpetrated against them by male intimates in the previous 6 months at each interview (or in the past 10 weeks at Time 2) rather than in the previous 12 months. Each of the CTS items was scored on the following 6-point response scale: $1=$ never, 2 = one time per month or less, $3=$ two to three times per month, $4=$ one to two times per week, $5=$ three to four times per week, and $6=$ more than four times per week. In addition, several of the original CTS items were split into two separate items for this study, and three other physical abuse items were added but followed the same format (i.e., "How often did he: break your glasses or tear your clothing; drive recklessly; tie up or physically restrain you?"). The mean frequency for all 15 physical aggression items was computed into a single score for each woman $\left(M_{\text {Time } 1}=\right.$ $\left.2.3, S D_{\text {Time } 1}=0.80 ; M_{\text {Time } 2}=2.1, S D_{\text {Time } 2}=0.34\right)$. The CTS is the most widely used instrument for assessing the frequency and severity of family violence and has good evidence of reliability and 
validity (Straus, 1990). Internal consistency reliability for the modified CTS violence subscale in the present study was .87 at Time 1 and .92 at Time 2.

Several other violence items were included for analysis. One item measured the frequency of forced sexual activity, using the same response format as above $\left(M_{\text {Time } 1}=2.5, S D_{\text {Time } 1}=1.7 ; M_{\text {Time } 2}=\right.$ $\left.0.10, S D_{\text {Time } 2}=0.48\right)$. In addition, women were asked to indicate whether they had sustained any of the following injuries in the past 6 months (or past 10 weeks at Time 2): cuts, scrapes, or bruises; broken bones or fractures; dislocated joints; soreness without bruises; burns; loose or broken teeth; internal injuries; strains or sprains; miscarriage; and knife or gunshot wound. A single score was assigned for the number of different types of injuries sustained, with a possible range of 0 to $10\left(M_{\text {Time } 1}=3.1, S D_{\text {Time } 1}=1.8\right.$; $M_{\text {Time 2 }}=0.36, S D_{\text {Time 2 }}=1.1$ ).

Violence as a Time 1 Predictor. The summed, standardized scores for the abuser's violent actions (15 physical violence items), forced sex (1 item), and number of types of injuries sustained by the woman (10 items) comprised the index variable for the extent of violence. Higher scores indicated a greater extent of violence. Although these three components of the violence are composed of different numbers of items, a simple composite score is usually preferable to more complicated weighting schemes that tend to be less valid and stable across various conditions (Grice, 2001).

Violence as a Time 2 Predictor. Because $70 \%$ of the women in the sample did not experience any abuse or injuries at the 10-week follow up, the corresponding violence variable for Time 2 was highly skewed. Using the same physical violence, forced sex, and injury items, respondents were classified into three mutually exclusive groups: (a) women who reported no abuse by any assailant in the past 10 weeks, (b) women who reported experiencing some physical abuse but no rape or injury in the past 10 weeks, and (c) women who reported experiencing some physical abuse plus injuries and/or rape. The violence variable at Time 2 included abuse by the original as well as a new assailant. 


\section{Secondary Stressors}

Attachment/Loss. A true-false 15-item checklist created for the original study asked respondents about their feelings toward their abusive partners. The instrument included many items that focused on lingering positive feelings of attachment toward the partner such as "When things are going well with us, I don't need anyone but him"; "I don't think I could find another man to love the way I love him"; and "I feel good about myself when I'm with him." At the same time, a number of the items included feelings that seem closely related but are typically considered to be characteristic of grieving or loss, such as a preoccupation with or longing for the ex-partner and feelings of emptiness (Gray, Koopman, \& Hunt, 1991; Gray \& Shields, 1992; Parkes, 1969): "When I try to imagine never seeing him again, I feel empty"; "I suppose I should be interested in other people and activities, but I just want to be with him"; and "Often . . . I find myself contacting him against my better judgment."1 These three items are similar to those on other grief scales that have been developed for divorcing men and women, based on Bowlby's (1982) three phases of mourning (e.g., see Gray \& Shields, 1992). Cronbach's alpha for the 15 items was .82 at Time 1 and .86 at Time 2 .

Family Responsibilities. A single-item measure of family responsibilities asked, "How do you feel about the responsibilities you have for members of your family?" Responses followed a 7-point Likert-type scale format, ranging from (1) extremely pleased to (7) terrible $\left(M_{\text {Time } 1}=2.7, S D_{\text {Time } 1}=1.4 ; M_{\text {Time 2 }}=2.6, S D_{\text {Time 2 }}=1.5\right)$.

Income Loss. The (potential) loss of household income due to separation from the assailant was calculated by taking the difference between women's personal monthly income at Time 3 (because this information was not available for half of the sample at Time 2) and the couple's total monthly household income from the preceding year. On average, women lost $\$ 3,325$ per month (SD $=11,235)$ as a result of the separation.

\section{Level of Stress Exposure}

An index variable was created to represent overall level of exposure to stress. First, the standardized scores for the secondary 
stressors (attachment/loss, family responsibilities, and income loss) were added together. This score was then added to women's standardized scores for violence at both Time 1 and Time 2 .

\section{Coping Resources}

The effects of both external (material/financial assets, social support) and internal resources (self-efficacy) were assessed. Although these constructs were conceptualized under the rubric of coping resources, they were treated as separate variables to assess individual effects on postseparation depression.

\section{Social Support}

A 9-item scale developed by Bogat, Chin, Sabbath, and Schwartz (1983) assessed women's perceived overall support as well as the quantity and quality of social support in four specific areas: practical assistance, advice and information, emotional support, and companionship. For each item, responses were scored on a 7-point scale ranging from extremely pleased to terrible. All items were reverse coded so that higher scores indicate greater social support. A single score was then calculated by averaging scores across all items $\left(M_{\text {Time 1 }}=5.1, S D_{\text {Time 1 }}=0.97 ; M_{\text {Time 2 }}=5.4\right.$, $\left.S D_{\text {Time } 2}=0.98\right)$. Cronbach's alpha for this scale was .85 at Time 1 and .90 at Time 2 .

\section{Socioeconomic And Material Assets}

This variable was a composite of the summed, standardized scores for employment status (working or not working), receiving public assistance (yes or no), years of education (less than high school, high school graduate, some college), and whether a woman had access to a car.

\section{Self-Efficacy}

This measure involved three hypothetical situations related to getting a job, finding a place to live, and finding cheap furniture. For each of the three hypothetical situations, the respondent was first asked to assess her degree of confidence in her own ability to carry out necessary actions on a 7-point scale $\left(M_{\text {Time } 1}=6.0, S D_{\text {Time } 1}\right.$ 
$\left.=1.2 ; M_{\text {Time } 2}=6.1, S D_{\text {Time } 2}=1.0\right)$. She was then asked to rate her confidence in how effective a friend would be in the same three hypothetical situations if the friend followed the respondent's advice $\left(M_{\text {Time } 1}=5.5, S D_{\text {Time } 1}=1.1 ; M_{\text {Time } 2}=5.8, S D_{\text {Time } 2}=0.95\right)$. Responses for these six items were given on a 7-point scale ranging from very certain to very uncertain. Scores for all six items were then standardized and combined into a single scale with an internal consistency of .85 at Time 1 and .79 at Time 2 .

\section{Depression}

The Center for Epidemiological Studies Depression Scale (Radloff, 1977) is a widely used self-report checklist of depressive symptoms with well-established validity and reliability for use in a variety of populations (e.g., see Berndt, 1990; Orme, Reis, \& Herz, 1986; Radloff, 1977; Rounsaville \& Weissman, 1978; Weissman, Sholomskas, Pottenger, Pruoff, \& Locke, 1977). The 20 items assess depression within the past week and include statements such as "I felt sad," "I talked less than usual," "I thought my life had been a failure," and "I could not 'get going." " Possible responses range from (1) never or rarely bothered to (4) bothered most or all of the time. Scores were averaged across the 20 items. The severity of depression scale used in this study is equivalent to that recommended by Radloff (1977) (although the raw scores differ): no depression $=1.00$ to 1.79 , mild depression $=1.80$ to 2.03 , moderate depression $=2.04$ to 2.54 , and severe depression $=2.55$ to 4.00 . Internal consistency was .86 at Time 1 , and similar findings were observed for the other five time points. At Time 1, the average depression score fell in the moderate range $\left(M_{\text {Time } 1}=2.33, S D_{\text {Time } 1}=\right.$ 0.62 ) but dropped to the none to mildly depressed range at all other time points.

\section{ANALYSES}

Growth curve analysis with SAS PROC MIXED was used to examine longitudinal "growth" trends or trajectories in depression over a 2-year period, Time 2 through Time 6, for subgroups that varied with respect to exposure to stressors at shelter exit (Time 1) or the 10-week follow up (Time 2). The sample was split into thirds by level of stress, rather than in half, so that we could 
examine the more extreme cases. Growth trends were assessed through a series of interactions between time and the stressor index variable. Such models assume a particular pattern of change over time for a given outcome that has been measured over multiple occasions. Because data for more than two time points were available, higher order polynomials were also considered to determine the shape of the curve. In at least one case, a plot of the group means over time indicated the need for the inclusion of a quadratic term as well. Quadratic parameters are appropriate where there is a positive or negative "bend" in the slope such that the rate of change in depression is accelerated.

Growth curve analyses calculate a separate intercept and slope for every individual in the sample. Such random effects models control for the high correlations among repeated measures of the same individuals over time (Bryk \& Raudenbush, 1992; Murray \& Wolfinger, 1994; Singer et al., 1998; Williamson, Appelbaum, \& Epanchin, 1991). We used the growth models to compare how the upper, middle, and lower thirds of the sample, ${ }^{2}$ ranked by level of exposure to stressors at shelter exit or the 10-week follow up, differed in the pattern and rate of change in depression over time. We also tested for trends over time for women within the various stress levels, such as whether the rate of change in depression differed significantly from zero. In the full model, explanatory and control variables (baseline levels of depression, social support, self-efficacy, and financial and material assets, the experimental condition) were added as fixed effects to examine how much they accounted for variation in the slope. The estimates for both the variance/covariance and beta coefficients were obtained by restricted maximum likelihood methods. The $t$ ratio provided the significance tests for the within-group changes in depression over time $\left(\beta_{\text {slope }} \neq 0\right)$.

Separate analyses were conducted for Time 1 and Time 2 predictor variables. Time 1 predictors are of interest because intervention efforts will be aided if long-term depression can be predicted while women are still in contact with an agency. However, a substantial number of women remain in contact with a shelter (or other agency) for several weeks or months beyond their initial stay through nonresidential services (e.g., support groups, advocacy interventions). In addition, because women's shelter stays typically mark a time of acute crisis in that levels of depression 
and other aspects of well-being are in a state of flux (e.g., Campbell, Sullivan, \& Davidson, 1995), it is not known how effectively the information obtained at Time 1 will predict depression more than 2 years later. For these reasons, corresponding predictor variables at Time 2 were also included in a separate analysis. (For more information on the study's design, see Anderson, 2001.)

\section{RESULTS}

\section{BIVARIATE RELATIONSHIPS AMONG THE MAJOR VARIABLES}

For the sample as a whole, there was marked improvement in the mean level of depression in the 10 weeks following women's shelter exit (i.e., from Time 1 to Time 2 ). The unadjusted mean levels of depression for the 94 women in the study, which fell within the moderately depressed range at Time 1 (2.33), dropped to the none to mildly depressed range 10 weeks later (1.87) and remained at that level over the 2 -year span. These data provide a general overview of trends as well as a baseline for comparison in later analyses. Table 1 displays the one-tailed significance tests of the correlations between the predictor and outcome variables. All three groups of predictor variables were correlated with depression in the expected direction. Although the violence and secondary stressors were related to higher levels of depression, the coping resources were negatively associated with depression. As a group, secondary stressors appeared to be most consistently and strongly related to depression. In addition, the strength of the correlations between secondary stressors and depression appeared to be increasing rather than decreasing with time. ${ }^{3}$ These aggregate statistics, however, are limited in that they cannot simultaneously control for the effects of multiple factors on depression. Most importantly, they can mask important differences among women who vary with respect to the stressors they face and the coping resources they possess.

\section{INTERACTIONS BETWEEN STRESSORS AND TIME}

The growth curve analyses tested for the presence of cumulative adversity in two ways. First, relative group differences in 
Table 1

Correlations Between Time 1 and Time 2 Independent Variables and Psychological Well-Being Over Time ${ }^{a}$

\begin{tabular}{|c|c|c|c|c|c|c|}
\hline & \multicolumn{6}{|c|}{ Depression } \\
\hline & Time 2 & Time 3 & Time 4 & Time 5 & Time 6 & Time 2 to Time $6^{\mathrm{b}}$ \\
\hline \multicolumn{7}{|l|}{ Time 1 predictors } \\
\hline Violence & $.17^{*}$ & .12 & $.25^{* *}$ & .12 & .11 & $.19^{*}$ \\
\hline \multicolumn{7}{|l|}{ Secondary stressors } \\
\hline Index variable & $.28^{* *}$ & $.23^{*}$ & $.18^{*}$ & $.34^{* * *}$ & $.40^{* * *}$ & $.36^{* * *}$ \\
\hline Family responsibilities & $.26^{* *}$ & .11 & $.29^{* *}$ & $.40^{* * *}$ & $.39^{* * *}$ & $.36^{* * *}$ \\
\hline Income loss & .12 & $.15+$ & .08 & $.19^{*}$ & $.27^{* *}$ & $.21^{*}$ \\
\hline Attachment/loss & .13 & $.15+$ & .03 & .02 & .06 & .08 \\
\hline \multicolumn{7}{|l|}{ Coping resources } \\
\hline Index variable & $-.22^{*}$ & $.15+$ & $-.35^{* * *}$ & $-.21^{* * *}$ & $-.13+$ & $-.26^{* * *}$ \\
\hline Financial and material & .10 & .06 & .16 & -.10 & -.08 & -.12 \\
\hline Social support & $-.33^{* * *}$ & $.23^{*}$ & $-.30^{* *}$ & $-.30^{* *}$ & -.25 & $-.35^{* * *}$ \\
\hline Self-efficacy & .11 & .07 & $-.26^{* *}$ & -.10 & -.04 & $-.15+$ \\
\hline \multicolumn{7}{|l|}{ Time 2 predictors } \\
\hline Violence & $.20^{*}$ & .02 & .09 & $.28^{* *}$ & $.30^{* *}$ & $-.22 *$ \\
\hline \multicolumn{7}{|l|}{ Secondary stressors } \\
\hline Index variable & $.38^{* * *}$ & $.31^{* * *}$ & $.32^{* * *}$ & $.33^{* * *}$ & $.52^{* * *}$ & $.46^{* * *}$ \\
\hline Family responsibilities & $.30^{* *}$ & $.23^{* *}$ & $.36^{* * *}$ & $.41^{* * *}$ & $.45^{* * *}$ & $.43^{* * *}$ \\
\hline Income loss & $.18^{*}$ & $.16+$ & $.14 \dagger$ & $.20^{*}$ & $.31^{* *}$ & $.24^{*}$ \\
\hline Attachment/loss & $.20^{*}$ & $.16+$ & .05 & .07 & $.14+$ & .11 \\
\hline \multicolumn{7}{|l|}{ Coping resources } \\
\hline Index variable & $-.36^{* * *}$ & $-.19 *$ & $-.32^{* *}$ & $-.33^{* *}$ & $-.25^{* *}$ & $-.35^{* * *}$ \\
\hline Financial and material & $-.19^{*}$ & -.11 & $-.16+$ & $-.15 t$ & .08 & $-.16+$ \\
\hline Social support & $-.47^{* * *}$ & $-.33^{* * *}$ & $-.42^{* * *}$ & $-.39 * * *$ & $-.44^{* * *}$ & $-.50 * * *$ \\
\hline Self-efficacy & $-.20^{*}$ & -.07 & $-.18^{*}$ & $-.22^{*}$ & -.11 & $-.19^{*}$ \\
\hline \multicolumn{7}{|l|}{ Control variables } \\
\hline Time 1 depression & $.45^{* * *}$ & $.46^{* * *}$ & $.45^{* * *}$ & $.30^{* *}$ & $.42^{* * *}$ & $.52^{* * *}$ \\
\hline
\end{tabular}

NOTE: $n=90$ to 94 .

a. Results are from one-tailed probability tests.

b. Correlations with average depression score over the five time points.

${ }^{*} p<.05 .{ }^{* *} p<.01 .{ }^{* * *} p<.001 .+p<.10$.

depression growth rates were specifically addressed through a series of group-by-time interactions. In other words, the change over time for one group can be more or less positive than that of another group. Second, actual rates of change in depression within groups over time were tested via the $t$ statistic to see if the slopes differed significantly from zero.

First, note in Model 1 of Table 2 that the main effect of time is not significant, which indicates there was no change in the level of depression over the 2-year period for the sample as a whole. Taking the analysis one step further, however, there were changes in depression over time that differed by level of exposure to 
stressors at the time of shelter exit, as predicted. The results in Model 2 show that the slope or rate of change in depression from Time 2 to Time 6 was more negative for the lowest stress group at shelter exit (but not the middle one third) compared with women who experienced the highest levels of stress. In other words, women who were exposed to the lowest amounts of violence and secondary stressors at shelter exit experienced a significantly greater decline in the level of depression over time. In Model3, the stressor variable remained significant over and above the effects of baseline depression and coping resources. As predicted, Time 1 social support was negatively (although not strongly) related to depression over time $(p<.10)$ and was the only resource to approach significance. None of the stress-resource variable interactions were significant. Finally, the random effects at the bottom of Table 2 indicate that significant variation in the 94 intercepts (i.e., the level of depression at Time 2 for a given individual) is still unaccounted for by the fixed effects or group characteristics in each of the models.

The same growth analysis (Model 3) also tested whether the group slopes, or rate of change in depression over time by level of exposure to stress at Time 1, were no different from zero. The fanlike spread in depression scores over time for the lower and upper one third of the sample can be seen in Figure 1. The figure displays a plot of the means adjusted for covariates (access to coping resources and baseline levels of depression) for each of the five time points. Additional results from the growth curve analysis are shown to the right of Figure 1. Although the most highly stressed women at Time 1 did not undergo a significant increase in level of depression, their scores did not improve with time. At the same time, those who were exposed to the lowest levels of violence and secondary stressors experienced a steady decline in the average level of depression as time progressed. All else being equal, a woman who ranked in the bottom one third in terms of stress exposure at shelter exit is predicted to score just below the mild range of depression (1.75) at 10 weeks following shelter exit. Two years later, the same woman could expect a further substantial and significant drop in her average level of depression (1.55), where she would place well out of the depressed range. In contrast, a woman who placed in the highest stress category at Time 1 would still be expected to report moderate levels of depression at 
Table 2

Growth Model for Changes in Depression Over a 2-Year Period Following Shelter Exit, by Time 1 Level of Exposure to Violence and Secondary Stressors

\begin{tabular}{|c|c|c|c|c|c|c|c|}
\hline \multirow[b]{2}{*}{ Time 1 Predictor Variable } & \multicolumn{2}{|l|}{ Model 1} & \multirow[t]{2}{*}{ Model 2} & \multicolumn{2}{|r|}{ Model 3} & \multirow[b]{2}{*}{ Coefficient } & \multirow[b]{2}{*}{ SE } \\
\hline & Coefficient & SE & & Coefficient & SE & & \\
\hline \multicolumn{8}{|l|}{ Fixed effects } \\
\hline Intercept & $1.90^{* * *}$ & .06 & & $1.97^{* * *}$ & .10 & $1.95^{* * *}$ & .08 \\
\hline Time & -0.01 & .02 & & 0.02 & .03 & 0.02 & .02 \\
\hline Stressors (lowest) & & & & -0.16 & .14 & -0.12 & .12 \\
\hline Stressors (middle) & & & & -0.07 & .14 & -0.04 & .12 \\
\hline Stressors (highest) & & & & - & - & - & - \\
\hline Social support & & & & & & $-0.09+$ & .05 \\
\hline Depression & & & & & & $0.40^{* * *}$ & .08 \\
\hline Time $\times$ Stressors $($ low $)$ & & & & $-0.09^{*}$ & .04 & $-0.09^{*}$ & .04 \\
\hline Time $\times$ Stressors $(\mathrm{mid})$ & & & & -0.00 & .04 & -0.00 & .04 \\
\hline \multirow[t]{2}{*}{ Time $\times$ Stressors (high) } & & & & - & - & - & - \\
\hline & Variance & z Coefficient & & Variance & z Coefficient & Variance & z Coefficient \\
\hline \multicolumn{8}{|l|}{ Random effects } \\
\hline Intercept & $.19^{* * *}$ & 4.14 & & $.19^{* * *}$ & 4.11 & $.11^{* * *}$ & 3.16 \\
\hline Slope & - & - & & .00 & .20 & .00 & .21 \\
\hline
\end{tabular}

NOTE: All models represent depression from Time 2 to Time $6 . n=94$.

${ }^{*} p<.05 .{ }^{* *} p<.01 .{ }^{* * *} p<.001 .+p<.10$. 


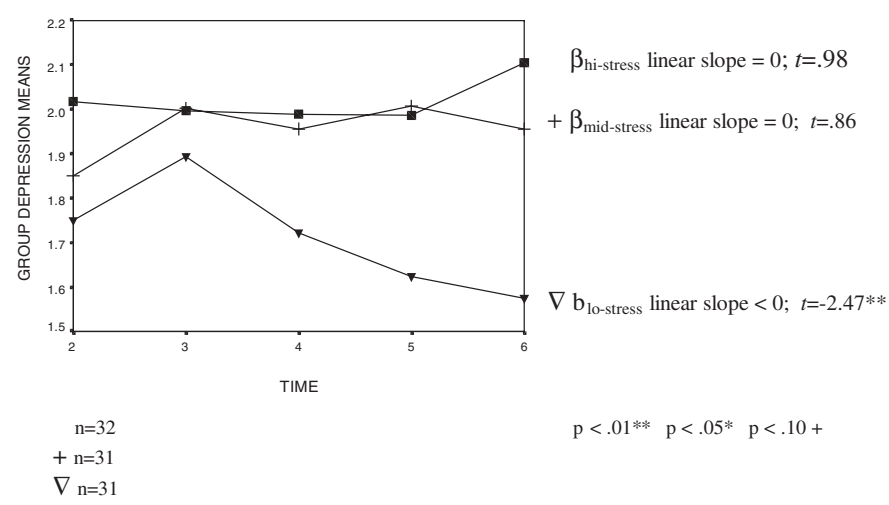

Figure 1 Changes in Mean Levels of Depression From Time 2 to Time 6, by Level of Exposure to Stressors at Shelter Exit

Time 6, more than 2 years later (2.10). Hence, the estimated depression score a full 2 years later for a woman who endured the most severe exposure to stressors rivals those observed in women at the time of shelter exit (2.10 and 2.33, respectively).

Another set of growth curve analyses (shown on Table 3) were conducted in parallel with those described above but with Time 2 instead of Time 1 predictors in the model. The significant coefficients for the two time by stress interactions in Model 3 reveal that women with the highest exposure to stress at the 10-week follow up became more depressed with time relative to the other two thirds of the sample. Although the linear slopes in Model 3 indicate (at least) a constant rate of change in depression over time, the significant quadratic terms in Model 4 signify a bend in the slope(s) such that the relative changes in depression by level of stress are occurring at an accelerated rate. Finally, stressors remained significant over and above the effects of the various coping resources and the experimental condition. ${ }^{4}$ Social support was strongly related to lower levels of depression between Time 2 and Time 6. Once again, financial and material assets and self-efficacy (not shown) were nonsignificant, and their inclusion did not alter the results.

Figure 2 displays the spread in the means by level of stress adjusted for covariates. The results to the right of the figure indicate that the linear increase in depression over time for women with the greatest exposure to stress at Time 2 was significantly different from zero. Changes in the level of depression did not differ 
Table 3

Growth Model for Changes in Depression Over a 2-Year Period Following Shelter Exit, by Time 2 Level of Exposure to Violence and Secondary Stressors

\begin{tabular}{|c|c|c|c|c|c|c|c|c|}
\hline \multirow[b]{2}{*}{ Time 2 Predictor Variable } & \multicolumn{2}{|c|}{ Model 1} & \multicolumn{2}{|c|}{ Model 2} & \multicolumn{2}{|c|}{ Model 3} & \multicolumn{2}{|c|}{ Model 4} \\
\hline & Coefficient & SE & Coefficient & SE & Coefficient & SE & Coefficient & SE \\
\hline \multicolumn{9}{|l|}{ Fixed effects } \\
\hline Intercept & $1.91^{*}$ & .07 & $2.03^{*}$ & .10 & $1.95^{*}$ & .11 & $2.02^{*}$ & .11 \\
\hline Time & -0.00 & .02 & $0.05^{* * *}$ & .03 & $0.05^{* * *}$ & .03 & -0.10 & .09 \\
\hline Stress (lowest) & & & $-0.28^{* * *}$ & .14 & -0.05 & .13 & -0.19 & .14 \\
\hline Stress (middle) & & & -0.08 & .14 & -0.07 & .12 & -0.20 & .13 \\
\hline Stress (highest) & & & - & - & - & - & - & - \\
\hline Social support & & & & & $-0.18^{*}$ & .05 & $-0.18^{*}$ & .05 \\
\hline Depression (Time 1) & & & & & $0.34^{*}$ & .08 & $0.34^{*}$ & .08 \\
\hline Experimental condition & & & & & 0.01 & .09 & 0.01 & .09 \\
\hline Stress × Time (lowest) & & & $-0.08^{* * *}$ & .04 & $-0.08^{* * *}$ & .04 & 0.19 & .12 \\
\hline Stress $\times$ Time (middle) & & & $-0.08^{* * *}$ & .04 & $-0.08^{* * *}$ & .04 & 0.18 & .12 \\
\hline Stress $\times$ Time (highest) & & & - & - & - & - & - & - \\
\hline$(\text { Time })^{2}$ & & & & & & & $0.04 \dagger$ & .02 \\
\hline (Time) ${ }^{2} \times$ Stress (lowest) & & & & & & & $-0.07^{* * *}$ & .03 \\
\hline (Time) ${ }^{2} \times$ Stress (middle) & & & & & & & $-0.07^{* * *}$ & .03 \\
\hline \multirow[t]{2}{*}{ (Time) ${ }^{2} \times$ Stress (highest) } & & & & & & & - & - \\
\hline & Variance & z Coefficient & Variance & z Coefficient & Variance & z Coefficient & Variance & z Coefficient \\
\hline \multicolumn{9}{|l|}{ Random effects } \\
\hline Intercept & $.21^{*}$ & 4.34 & $.20^{*}$ & 4.23 & $.11^{*}$ & 3.20 & $.11^{*}$ & 3.24 \\
\hline Slope & - & - & .00 & 0.56 & .00 & 0.56 & .00 & 0.65 \\
\hline
\end{tabular}

NOTE: All models represent depression from Time 2 to Time $6 . n=90$. The four (Time) ${ }^{2}$ coefficients represent the quadratic term. ${ }^{*} p<.001 .{ }^{* *} p<.01 .{ }^{* * *} p<.05 .+p<.10$. 


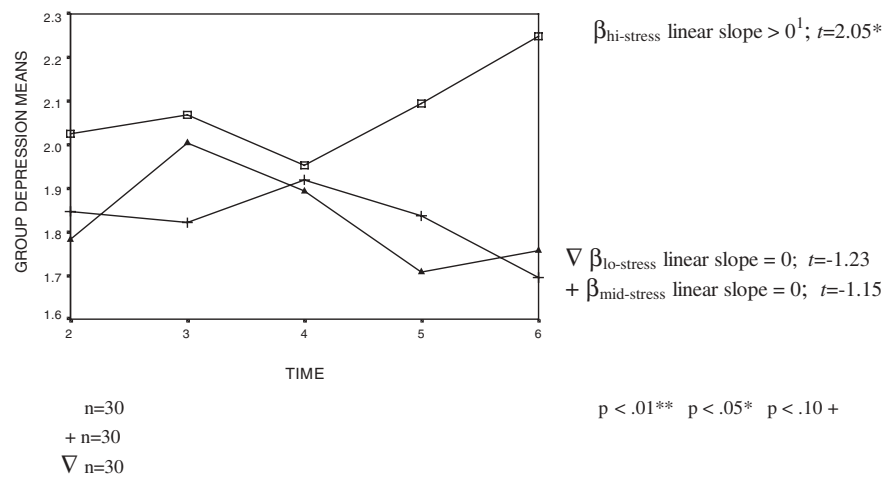

1: There is a trend toward a significant "+" quadratic slope for the highest stress group $(t=1.84+)$.

Figure 2 Changes in Mean Levels of Depression From Time 2 to Time 6, by Level of Exposure to Stressors at the 10-Week Follow Up

significantly from zero for those exposed to lower levels of stress, but the negative quadratic trend or decrease in depression for these women neared significance. ${ }^{5}$ At more than 2 years postshelter, point estimates from the full model predict the depression score for women exposed to the highest levels of stress, with other variables being held constant, to be similar to those reported by battered women just leaving the shelter, when many are still in crisis ( 2.29 versus 2.33 , respectively). In addition, if the same women are also one standard deviation below the mean in their access to social support at the 10-week follow up, by Time 6 their depression scores are expected to fall in the highmoderate range (2.43), which equals or exceeds that of women exiting the shelter at Time 1.

We also tested whether the results differed by race (White $n=$ 37 , non-White $n=57$ ). The main effect of race and a stress by race interaction term were added to the growth models with the Time 1 and Time 2 predictors. The coefficients for the main and interaction effects were nonsignificant regardless of which variables were included in the models.

\section{DISCUSSION}

Despite the considerable courage and perseverance required of women who are in the process of leaving an abusive partner (e.g., 
Hoff, 1990; Kirkwood, 1993; Moss, Pitula, Campbell, \& Halstead, 1997), circumstances after separation can threaten to undermine their psychological well-being. This study developed from a need to identify, early in the process of leaving, battered women who are most at risk for negative long-term psychological outcomes, so that prevention efforts can be implemented. As the findings indicate, the postseparation process can lead to diverse outcomes even among women who are quite homogeneous in terms of socioeconomic status and history of violence. The strength of the relationships between the predictor variables and Time 6 depression is quite remarkable given the large time interval. Although levels of depression were very stable over the 2-year period for the sample as a whole, quite different trajectories were uncovered by level of exposure to stressors shortly after the time of shelter exit.

Growth trends were consistent with the notion of cumulative adversity such that the gap in depression between groups continued to widen over the 2-year period. Depression for the most highly stressed women at Time 1 remained at moderate levels even at the 26-month follow-up. Moreover, the negative effects of stressors measured at 10-weeks postshelter significantly increased with time for those in the highest stress category. This finding concurs with those in several studies of recent divorcees and sexual assault victims, which found that a substantial minority report low or decreased levels of long-term psychological well-being (e.g., Kitson, 1992; Resick \& Nishith, 1997). In the current study, these findings were uncovered through a fairly strict test of the hypotheses. Controlling for baseline levels of psychological depression made it possible to rule out poorer initial adjustment among the most highly stressed women.

Controlling for social support, self-efficacy, and financial and material resources at shelter exit did little to alter the effects of stressors on long-term depression. Self-efficacy, along with financial and material resources, was not related to depression even at the bivariate level. In part, the weak effects of financial and material factors most likely reflect their low variation as most of the women had meager economic resources to assist them in coping with major stressors. Social support at Time 2 exerted a strong compensatory effect on depression that did not differ by level of exposure to stress. Likewise, several other studies of battered women also found independent, positive effects of social support 
on psychological well-being but did not uncover significant interaction effects of such resources with stressors (e.g., Astin, Lawrence, \& Foy, 1993; Kemp et al., 1995; Tan, Basta, Sullivan, \& Davidson, 1995).

The findings from this investigation can only be generalized to samples of women who have at some point used domestic violence shelters. These women are, however, worthy of study as they are among the poorest, most severely abused, and most in need of services. A greater concern is not the lack of representativeness but rather a lack of variability in some measures such as the extent of abuse and financial resources. Without comparison groups of nonabused, divorcing women from the community and abused, nonsheltered women, the potentially powerful impact of such variables on depression was likely attenuated. In addition, the relatively small sample size placed some limits on the number of variables that could be included in the statistical analyses.

The theoretical contributions of this investigation can be applied to the study of other populations. We have extended Pearlin's (1999b) stress-process model, first, by articulating several possible long-term outcomes, including the homeostatic and cumulative adversity responses to stress. Second, we have identified specific conditions that can lead to patterns of cumulative adversity. These conditions are likely to involve multiple major stressors that collectively result in very high levels of stress for some individuals and may be compounded by a lack of access to key resources.

The growth curve analyses generated findings that add to the current body of knowledge on depression in battered women. This study found a relationship between exposure to multiple stressors and changes in depression over time. Although previous studies have confirmed the link between various stressors such as domestic violence and depression longitudinally (e.g., Sutherland, Bybee, \& Sullivan, 1998), this investigation uncovered increasing disparities in depression over the 2-year period among those differentially exposed to stressors at an earlier time point.

This study also has practice and policy implications. It constitutes one of the few quantitative attempts to identify factors associated with battered women's well-being (in this case, depression) after separation from the assailant. Moreover, it is unique in its attempt to predict long-term trends based on information given 
by the women around the time of shelter exit. The finding that those most at risk for long-term depression can be identified early in the course of their contact with an agency can be very useful to practitioners. Results from the study can directly inform the efforts of policy makers and service providers with respect to (a) the timing of intervention efforts, (b) key factors affecting women's long-term postseparation depression, (c) the population to be given highest priority, and (d) the types of assistance that can help to alleviate separated battered women's distress over time. The need for early intervention was made clear by the growing inequalities in long-term depression by stress level and the likelihood of cumulative depression spirals among women with the highest stress and fewest resources. Such trends may be more resistant to change efforts once they have gained momentum. Greater access to coping resources can provide women with more and better response options before a downward spiral develops. In this study, social support was the most effective personal resource, perhaps because it can broadly encompass women's needs for companionship, advice and information, financial backing, and temporary food and shelter provisions. Social support for this very poor group of women may have compensated in part for the lack of other resources such as personal income and housing.

Policy and intervention, therefore, should aim to bolster the various types of support available to these women. Women's support groups with a special focus on postseparation issues, such as emotional loss and lifestyle changes, can foster feelings of selfefficacy, empowerment, and identification with peers who are struggling with similar life situations. Although interventions focusing on emotional support can be extremely valuable, it may be difficult for many women to feel fully empowered when they continue to face the threat of further violence and the lack of economic security. Postshelter advocacy interventions and other follow-up programs also provide social support in the form of knowledge and professional advice. These services further empower women by linking them with community resources to address legal, financial, and other needs, and women have reported many positive outcomes, including higher perceived quality of life (Sullivan \& Bybee, 1999; Sullivan, Campbell, Angelique, Eby, \& Davidson, 1994; Tutty, 1998). 
Women particularly need material resources. In a number of divorce and battered women studies, many of the worries women expressed around family responsibilities stemmed from economic deficits in the household (e.g., Levendosky, Lynch, \& Graham-Bermann, 2000; Voydanoff \& Donnelly, 1998). Although friends, relatives, and battered women's shelters can provide temporary aid and shelter, long-term solutions are sorely needed for separated women. A majority (83\%) of the women in this study were receiving public assistance. Low-income women often have a great deal of difficulty in securing safe and affordable housing, and services targeting such needs are relatively rare (Correia, 2001). Advocates and activists are calling for a variety of other programs that address economic issues, including the following: low-cost or on-site quality child care for low-income families, more flexible work policies for single mothers such as work-athome arrangements, support for long-term housing, education and job-training programs, automatic increases in child support to match changes in the cost of living, and provisions for inexpensive transportation (Davies, 2001; Gondolf \& Fisher, 1988; Morgan, 1991; Skrypnek \& Fast, 1996).

Separated battered women will also need help to reduce postseparation violence and stalking. The results of such efforts in recent years offer some encouragement. Where no stalking laws existed in the United States prior to 1990, 5 years later all states had adopted such laws (Tjaden, Thoennes, \& Allison, 2000). Although the effectiveness of restraining orders and other stalking legislation has been questioned (e.g., Sherman, 1992; Tjaden \& Thoennes, 2000), the recent creation of stalking laws indicates increasing public awareness and concern for the problem of expartner violence.

There is a pressing need for studies that can inform service providers more specifically about which measures will be the most effective in promoting well-being among survivors before a downward spiral can gain momentum or low levels of well-being can become too firmly entrenched. Further research should seek to clarify the particular aspects of individual stressors that are most debilitating. A woman's concerns in the present study about family responsibilities, for instance, could relate to a wide range of issues, including worries about lack of financial security, her children's fears or adjustment problems, safety issues, and 
meeting the demands of multiple roles. In addition, research must determine which types of social support and other resources, alone and in combination, are the most valuable in terms of reducing or eliminating long-term depression.

Finally, future research will need to illuminate the mechanisms through which high levels of stress contribute to increasingly lower levels of well-being. The reasons for the widening gap in depression among those differentially exposed to stressors after shelter exit were not clear. Perhaps, higher levels of stress are more likely to trigger subsequent stressors that can manifest as chronic strains or a series of negative life events. The multiple stressors encountered by women who have separated from an abusive partner may serve as catalysts for a host of other negative events, such as repeated exposure to postseparation violence and loss of employment, or more chronic strains, such as depletion of key coping resources.

In conclusion, a major finding to emerge from this study is that the ecological stressors faced by these women are multiple, persistent, and often severe enough to result in depression spirals over time for a substantial minority of women, especially if there are few protective factors available to them. As progress continues through the efforts of battered women's advocates, greater access to needed coping resources will allow women to capitalize on the agency they already possess. In turn, this could lead to less depression for more women in the postseparation period. In time, hopefully, the only long-term spiral for most women following separation will be in a positive direction toward greater overall well-being.

\section{NOTES}

1. The data for this study lend support to the validity of this measure. In correlational analyses involving the entire sample $(n=278)$, the attachment/loss measure was significantly related to depression at all subsequent time points for battered women who were separated from the abuser, but the opposite was true for women who had returned to the abuser. For women who had returned, attachment appeared to have a weak, negative relationship to depression.

2. Grouping the sample into thirds seemed appropriate given the results from the Kitson (1992) study cited previously. The highest stress women constituted 33\% of the sample in this study. Hence, the proportion of those hypothesized to experience increases in 
depression over time approximates the proportion of divorcees in the Kitson study that reported lower levels of psychological adjustment 3 years after the initial interview.

3. It is not at all surprising that the violence is more modestly correlated with well-being over time. First, most of the women were quite severely beaten, and this results in less variability in exposure to violence. Second, the violence measures at Time 1 refer to the previous 6 months (or the past 10 weeks at Time 2) instead of the immediate circumstances around the time of the interviews.

4. A time-experimental condition interaction was also tested to examine the effect of the experimental condition on change in depression over time. The interaction was nonsignificant (not shown in Table 3).

5. Note the identical estimates in the coefficients for the lower and middle thirds of the sample in Table 3. When the number of parameters in the full model was reduced (from 15 to 12) by combining the lower two thirds of the sample, the quadratic change toward less depression was significant at $p<.05$.

\section{REFERENCES}

Aldwin, C., \& Stokols, D. (1988). The effects of environmental change on individuals and groups: Some neglected issues in stress research. Journal of Environmental Psychology, 8 , 57-75.

Anderson, D. (2001). Predicting long-term trends in psychological well-being in women who have left their abusive partners. Doctoral dissertation: University of Michigan.

Aneshensel, C. (1999). Outcomes of the stress process. In A. Horwitz \& L. Scheid (Eds.), A handbook for the study of mental health: Social contexts, theories, and systems (pp. 211-227). New York: Cambridge University Press.

Astin, M., Lawrence, K., \& Foy, D. (1993). Posttraumatic stress disorder among battered women: Risk and resiliency factors. Violence and Victims, 8, 17-28.

Balsam, K. (2001). Nowhere to hide: Lesbian battering, homophobia, and minority stress. Women \& Therapy, 23, 25-37.

Bartfield, J. (2000). Child support and the postdivorce economic well-being of mothers, fathers, and children. Demography, 37, 203-213.

Berman, W. (1988). The relationship of ex-spouse attachment to adjustment following divorce. Journal of Family Psychology, 1, 312-328.

Berndt, D. (1990). Inventories and scales. In B. Wolman \& G. Stricker (Eds.), Depressive disorders: Facts, theories, and treatment methods (pp. 255-274). New York: John Wiley.

Bianchi, S., Subaiya, L, \& Kahn, J. (1999). The gender gap in the economic well-being of nonresident fathers and custodial mothers. Demography, 36, 195-203.

Bogat, G., Chin, R., Sabbath, W., \& Schwartz, C. (1983). The adult's social support questionnaire (Technical Report 2). East Lansing: Michigan State University.

Bowlby, J. (1982). Attachment and loss: Retrospect and prospect. American Journal of Orthopsychiatry, 54(4), 664-678.

Brown, B., \& Foye, B. (1982). Divorce as a dual transition: Interpersonal loss and role restructuring. In V. Allen \& E van de Vliert (Eds.), Role transitions: Explorations and explanations (pp. 315-329). New York: Plenum.

Bryk, A., \& Raudenbush, S. (1992). Hierarchical linear models: Applications and data analysis methods. Newbury Park, CA: Sage.

Buehler, C., Hogan, M., Robinson, B., \& Levy, R. (1985). The parental transition: Divorcerelated stressors and well-being. Journal of Divorce, 9, 61-79.

Caldwell, R., \& Bloom, B. (1982). Social support: Its structure and impact on marital disruption. American Journal of Community Psychology, 10, 647-667. 
Campbell, J., \& Lewandowski, L. (1997). Mental and physical health effects of intimate partner violence on women and children. Psychiatric Clinics of North America, 20, 353374.

Campbell, J., \& Soeken, K. (1999). Women's responses to battering over time: An analysis of change. Journal of Interpersonal Violence, 14, 21-40.

Campbell, R., Sullivan, C., \& Davidson, W. (1995). Women who use domestic violence shelters: Changes in depression over time. Psychology of Women Quarterly, 19, 237-255.

Cherlin, A., Chase-Lansdale, P., \& McRae, C. (1998). Effects of parental divorce on mental health throughout the life course. American Sociological Review, 63, 239-249.

Correia, A. (2001). Housing and battered women: A case study of domestic violence programs in Iowa. Washington, DC: U.S. Department of Justice.

Davies, J. (2001). The new welfare law: State implementation and use of the Family Violence Option. Washington, DC: U.S. Department of Justice.

DeLongis, A., Folkman, S., \& Lazarus, R. (1988). The impact of daily stress on health and mood: Psychological and social resources as mediators. Journal of Personality and Social Psychology, 54, 486-495.

Dixon, C., \& Rettig, K. (1994). An examination of income adequacy for single women two years after divorce. Journal of Divorce and Remarriage, 22, 55-71.

Duncan, G., \& Hoffman, S. (1985). Economic consequences of marital instability. In M. David \& T. Smeeding (Eds.), Horizontal equity, uncertainty, and well-being (pp. 427-467). Chicago: University of Chicago Press.

Dutton, D., \& Painter, S. (1993). Emotional attachments in abusive relationships: A test of traumatic bonding theory. Violence and Victims, 8, 105-120.

Follette, V., Polusny, M., Bechtle, A., \& Naugle, A. (1996). Cumulative trauma: The impact of child sex abuse, adult sexual assault, and spouse abuse. Journal of Traumatic Stress, 9 , 25-35.

Gerstel, N., Riessman, C., \& Rosenfield, S. (1985). Explaining the symptomology of separated and divorced women and men: The role of material conditions and social networks. Social Forces, 64, 84-101.

Golding, J. (1999). Intimate partner violence as a risk factor for mental disorders: A metaanalysis. Journal of Family Violence, 14, 99-132.

Gondolf, E., \& Fisher, E. (1988). Battered women as survivors. Lexington, MA: Lexington Books.

Gray, C., Koopman, E., \& Hunt, J. (1991). The emotional phases of marital separation: An empirical investigation. American Journal of Orthopsychiatry, 61, 138-143.

Gray, C., \& Shields, J. (1992). The development of an instrument to measure the psychological response to separation and divorce. Journal of Divorce and Remarriage, 17, 43-56.

Grice, J. (2001). A comparison of factor scores under conditions of factor obliquity. Psychological Methods, 6, 67-83.

Henderson, A. (1992). Social support and depression. In H. Veiel \& U. Baumann (Eds.), The meaning and measurement of social support (pp. 85-92). New York: Hemisphere.

Herbert, T. B., Silver, R. C., \& Ellard, J. (1991). Coping with an abusive relationship: I. How and why do women stay? Journal of Marriage and the Family, 53, 211-325.

Hobfoll, S. (1989). Conservation of resources: A new attempt at conceptualizing stress. American Psychologist, 44, 513-524.

Hobfoll, S., Dunahoo, C., \& Monnier, J. (1995). Conservation of resources and traumatic stress. In J. Freedy \& S. Hobfoll (Eds.), Traumatic stress: From theory to practice (pp. 29-47). New York: Plenum.

Hoff, L. (1990). Battered women as survivors. New York: Routledge.

Hoffman, J., Cerbone, F., \& Su, S. (2000). A growth curve analysis of stress and adolescent drug use. Substance Use and Misuse, 35, 687-716. 
Holmes, T., \& Rahe, R. (1967). The social readjustment rating scale. Journal of Psychosomatic Research, 11, 213-218.

Humphreys, J. (1995). The work of worrying: Battered women and their children. Scholarly Inquiry for Nursing Practice, 9, 127-145.

Johnson, H. (1995). Risk factors associated with non-lethal violence against women by marital partners. In C. Block \& R. Block (Eds.), Trends, risks, and interventions in lethal violence: Proceedings of the Third Annual Spring Symposium of the Homicide Research Working Group (pp. 152-168). Washington, DC: National Institute of Justice.

Kemp, A., Green, B. L., Hovanitz, C., \& Rawlings, E. I. (1995). Incidence and correlates of posttraumatic stress disorder in battered women: Shelter and community samples. Journal of Interpersonal Violence, 10, 43-55.

Kiecolt-Glaser, J., Fisher, L., Ogrocki, P., Stout, J., Speicher, C., \& Glaser, R. (1987). Marital quality, marital disruption, and immune function. Psychosomatic Medicine, 49, 13-34.

Kirkwood, C. (1993). Leaving abusive partners: From the scars of survival to the wisdom for change. Newbury Park, CA: Sage.

Kitson, G. (1992). Portrait of divorce. New York: Guilford.

Koss, M., \& Mukai, T. (1993). Recovering ourselves: The frequency, effects, and resolution of rape. Research on battered women and their assailants. In F. Denmark \& M. Paludi (Eds.), Psychology of women: A handbook of issues and theories (pp. 478-512). Westport, CT: Greenwood.

Lerner, C. F., \& Kennedy, L. T. (2000.) Stay-leave decision making in battered women: Trauma, coping and self-efficacy. Cognitive Therapy and Research, 24, 215-232.

Levendosky, A., Lynch, S., \& Graham-Bermann, S. (2000). Mothers' perceptions of the impact of woman abuse on their parenting. Violence Against Women, 6, 247-271.

McGrath, J. (1970). A conceptual formulation for research on stress. In J. E. McGrath (Ed.), Social and psychological factors in stress (pp. 10-21). New York: Holt, Rinehart \& Winston.

Mechanic, M., Weaver, T., \& Resick, P. (2000). Intimate partner violence and stalking behavior: Exploration of patterns and correlates in a sample of acutely battered women. Violence and Victims, 15, 55-72.

Miller, D., Green, K., Causby, V., White, B., \& Lockhart, L. (2001). Domestic violence in lesbian relationships. Women $\mathcal{E}$ Therapy, 23, 107-127.

Molina, O. (1999). The effect of divorce on African American working women. Journal of Divorce and Remarriage, 32, 1-15.

Morgan, L. (1991). After marriage ends: Economic consequences for midlife women. Newbury Park, CA: Sage.

Moss, V., Pitula, C., Campbell, J., \& Halstead, L. (1997). The experience of terminating an abusive relationship from an Anglo and African American perspective: A qualitative descriptive study. Issues in Mental Health Nursing, 18, 433-454.

Murray, D., \& Wolfinger, R. (1994). Analysis issues in the evaluation of community trials: Progress toward solutions in SAS/STAT MIXED. Journal of Community Psychology, 22, 140-154.

Neville, H., \& Heppner, M. (1999). Contextualizing rape: Reviewing sequelae and proposing a culturally inclusive ecological model of sexual assault recovery. Applied and Preventive Psychology, 8, 41-62.

Orme, J., Reis, J., \& Herz, E. (1986). Factorial and discriminant validity of the Center for Epidemiological Studies Depression (CES-D) Scale. Journal of Clinical Psychology, 42, 28-33.

Parkes (1969). Separation anxiety: An aspect of the search for a lost object. Studies in Anxiety, 3, 87-92.

Pearlin, L. (1999a). Stress and mental health: A conceptual overview. In A. Horwitz \& L. Scheid (Eds.), A handbook for the study of mental health: Social contexts, theories, and systems (pp. 161-175). New York: Cambridge University Press. 
Pearlin, L. (1999b). The stress process revisited: Reflections on concepts and their interrelationships. In C. Aneshensel \& J. Phelan (Eds.), Handbook of the sociology of mental health (pp. 395-415). New York: Kluwer Academic/Plenum.

Pearlin, L., Lieberman, M., Menaghan, E., \& Mullan, J. (1981). The stress process. Journal of Health and Social Behavior, 22, 337-356.

Pledge, D. S. (1992). Marital separation/divorce: A review of individual responses to a major life stressor. Journal of Divorce \& Remarriage, 17, 151-181.

Radloff, L. (1977). The CES-D scale: A self-report depression scale for research in the general population. Applied Psychological Measurement, 1, 385-401.

Resick, P. (1993). The psychological impact of rape. Journal of Interpersonal Violence, 8, 223255.

Resick, P., \& Nishith, P. (1997). Sexual assault. In R. Davis, A. Lurigio, \& W. Skogan (Eds.), Victims of crime (pp. 27-52). Thousand Oaks, CA: Sage.

Roberts, G., Williams, G., Lawrence, J., \& Raphael, B. (1998). How does domestic violence affect women's mental health? Women and Health, 28, 117-129.

Rollstin, A., \& Kern, J. (1998). Correlates of battered women's psychological distress: Severity of abuse and duration of the postabuse period. Psychological Reports, 82, 387394.

Rosen, K., \& Stith, S. (1997). Surviving abusive dating relationships: Processes of leaving, healing, and moving on. In G. K. Kantor \& J. L. Jasinski (Eds.), Out of the darkness: Contemporary perspectives on family violence (pp. 170-182). Thousand Oaks, CA: Sage.

Rounsaville, B. (1978). Theories in marital violence: Evidence from a study of battered women. Victimology, 3, 11-31.

Rounsaville, B., \& Weissman, M. (1978). Battered women: A medical problem requiring detection. International Journal of Psychiatry in Medicine, 8, 191-202.

Sato, R., \& Heiby, E. (1992). Correlates of depressive symptoms among battered women. Journal of Family Violence, 7, 229-245.

Shapiro, A. D. (1996). Explaining psychological distress in a sample of remarried and divorced persons: The influence of economic distress. Journal of Family Issues, 17, 186203.

Sherman, L. (1992). Policing domestic violence: Experiments and dilemmas. New York: Maxwell Macmillan International.

Singer, B., Ryff, C., Carr, D., \& Magee, W. (1998). Linking life histories and mental health: A person-centered strategy. Sociological Methodology, 28, 1-51.

Skrypnek, B., \& Fast, J. (1996). Work and family policy in Canada: Family needs, collective solutions. Journal of Family Issues, 17, 793-812.

Solomon, Z., Oppenheimer, B., \& Noy, S. (1986). Subsequent military adjustment of combat stress reaction casualties: A nine-year follow-up study. Military Medicine, 151(1), 8-11.

Straus, M. (1979). Measuring intrafamily conflict and violence: The Conflict Tactics (CT) Scales. Journal of Marriage and the Family, 41, 75-88.

Straus, M. A. (1990). The Conflict Tactics Scale and its critics: An evaluation and new data on validity and reliability. In M. A. Straus \& R. J. Gelles (Eds.), Physical violence in American families: Riskfactors and adaptations to violence in 8145 families (pp. 49-73). New Brunswick, NJ: Transaction Publishing.

Sullivan, C., \& Bybee, D. (1999). Reducing violence using community based advocacy for women with abusive partners. Journal of Consulting and Clinical Psychology, 67, 43-53.

Sullivan, C., Basta, J., Tan, C., \& Davidson, W. (1992). After the crisis: A needs assessment of women leaving a domestic violence shelter. Violence and Victims, 7, 267-274.

Sullivan, C., Campbell, R., Angelique, H., Eby, K., \& Davidson, W. (1994). An advocacy intervention program for women with abusive partners: Six-month follow-up. American Journal of Community Psychology, 22, 101-122. 
Sutherland, C., Bybee, D., \& Sullivan, C. (1998). The long-term effects of battering on women's health. Women's Health Research on Gender, Behavior, and Policy, 4, 41-70.

Tan, C., Basta, J., Sullivan, C., \& Davidson, W. (1995). The role of social support in the lives of women exiting domestic violence shelters: An experimental study. Journal of Interpersonal Violence, 10, 437-451.

Thabes, V. (1997). Survey analysis of women's long-term, postdivorce adjustment. Journal of Divorce \& Remarriage, 27, 163-175.

Thiriot, T., \& Buckner, E. (1992). Multiple predictors of satisfactory post-divorce adjustment of single custodial parents. Journal of Divorce and Remarriage, 17, 27-48.

Tigert, L. (2001). The power of shame: Lesbian battering as a manifestation of homophobia. Women \& Therapy, 23, 73-85.

Tjaden, P., \& Thoennes, N. (2000). Extent, nature, and consequences of intimate partner violence: Findings from the National Violence Against Women Survey. Washington, DC: National Institute of Justice.

Tjaden, P., Thoennes, N., \& Allison, C. (2000). Comparing stalking victimization from legal and victim perspectives. Violence and Victims, 15, 7-22.

Turner, J., \& Wheaton, B. (1995). Checklist measurement of stressful life events. In S. Cohen, R. Kessler, \& L. Gordon (Eds.), Measuring stress: A guide for health and social scientists (pp. 29-53). New York: Oxford University Press.

Turner, R. J., \& Roxburgh, S. (in press). Psychological adjustment and the mothering role: A longitudinal assessment of the significance of life stress and social support. In P. Leaf (Ed.), Research in community and mental health. Greenwich, CT: JAI.

Tutty, L. (1998, July). The importance of follow-up programs for abused women. Paper presented at Program Evaluation and Family Violence Research: An International Conference, University of New Hampshire, Durham, NH.

Voydanoff, P., \& Donnelly, B. (1998). Parents' risk and protective factors as predictors of parental well-being and behavior. Journal of Marriage and the Family, 60, 344-355.

Walker, L. (1984). The battered woman syndrome. New York: Springer.

Weaver, T., \& Clum, G. (1996). Interpersonal violence: Expanding the search for long-term sequelae within a sample of battered women. Journal of Traumatic Stress, 9, 783-803.

Weissman, M., Sholomskas, D., Pottenger, M., Pruoff, B., \& Locke, B. (1977). Assessing depressive symptoms in five psychiatric populations: A validation study. American Journal of Epidemiology, 106, 203-213.

Wheaton, B. (1999). The nature of stressors. In A. Horwitz \& L. Scheid (Eds.), A handbook for the study of mental health: Social contexts, theories, and systems (pp. 176-197). New York: Cambridge University Press.

Wheaton, B., \& Gotlib, I. (1997). Trajectories and turning points over the life course: Concepts and themes. In H. Gotlib \& B. Wheaton (Eds.), Stress and adversity over the life course: Trajectories and turning points (pp. 1-25). New York: Cambridge University Press.

Wilcox, B. (1986). Stress, coping, and the social milieu of divorced women. In S. Hobfoll (Ed.), Stress, social support, and women (pp. 115-132). New York: Hemisphere.

Williamson, G., Appelbaum, M., \& Epanchin, A. (1991). Longitudinal analyses of academic achievement. Journal of Educational Measurement, 28, 61-76.

Woods, S. (2001). Prevalence and patterns of posttraumatic stress disorder in abused and postabused women. Issues in Mental Health Nursing, 21, 309-324.

Yoshihama, M., \& Horrocks, J. (2002). Post-traumatic stress symptoms and victimization among Japanese-American women. Journal of Consulting and Clinical Psychology, 70, 205-215.

Zuckerman, H. (1998). Accumulation of advantage and disadvantage: The theory and its intellectual biography. In C. Mongardini \& S. Tabboni (Eds.), Robert K. Merton and contemporary sociology (pp. 139-161). New Brunswick, NJ: Transaction Publishing. 
Deborah K. Anderson, Ph.D., is a National Institute of Mental Health postdoctoral research trainee at the University of Michigan's Institute for Research on Women and Gender. Her research focuses primarily on violence against women, women's psychological well-being, and the process of leaving abusive partners. Other research interests include evaluation of domestic violence training programs. She recently coauthored an article assessing the effectiveness of such a training program for child protection workers and their supervisors.

Daniel G. Saunders, Ph.D., is associate professor at the University of Michigan School of Social Work where he teaches courses on direct practice and domestic violence. His research on domestic violence focuses on abuser types and treatment, the traumatic aftermath of violent victimization, and the attitudes and responses of professionals. He was a postdoctoral research fellow at the Family Violence Research Program of the University of New Hampshire and a postdoctoral research fellow and associate scientist at the Department of Psychiatry at the University of Wisconsin-Madison. His professional publications have appeared in numerous journals and books.

Mieko Yoshihama, Ph.D., is associate professor at the University of Michigan School of Social Work. She is a steering committee member of the Asian and Pacific Islander Institute on Domestic Violence and serves on advisory boards for various national, state, and local organizations. She has conducted numerous community-based research projects on domestic violence in the United States and Japan, including a nationwide survey in Japan and a study of Japanese American and immigrant women in Los Angeles. Her research interests are violence against women, domestic violence in Asian Pacific Islander communities, immigrants and refugees, mental health, and community organizing.

Deborah I. Bybee, Ph.D., is associate professor of research in ecological/community psychology at Michigan State University. She has a primary interest in quantitative methods and how they can be used to understand complex, real-world phenomena, especially those that change over time. Substantively, she has applied her methodological interests to a variety of areas, including advocacy for women with abusive partners, intervention with children who have witnessed domestic violence, housing assistance for individuals who are homeless and mentally ill, education for individuals with mental illness, and mothering by women coping with a serious mental illness.

Cris M. Sullivan, Ph.D., is associate professor in ecological/community psychology at Michigan State University and director of evaluation for the Michigan Coalition Against Domestic and Sexual Violence. She has been an advocate and researcher in the movement to end violence against women since 1982. Her research has primarily involved examining the long-term effects of communitybased interventions for battered women and their children and evaluating domestic violence and sexual assault victim service programs. 